\title{
Epistemological Issues in African Higher Education
}

\author{
Kai Horsthemke
}

\author{
Introduction: Knowledge and Higher Education \\ on the African Continent
}

Higher education, and education generally, is a prime site for the transmission, facilitation, development and production of knowledge. This is a truism bordering on platitude. Universities, in particular, are defined in terms of the generation of knowledge. The debate over whether knowledge should be regarded as instrumental, for example in terms of personal or social progress, advancement and transformation, or whether it should (also) be treated as valuable in and for itself indicates only one of many epistemologically charged concerns in African higher education. In this chapter, I aim to provide an overview of a few of the epistemological issues that have arisen over the past few decades concerning higher education on the African continent. First and foremost, the ideas of indigenous (local, traditional) knowledge and knowledge systems, and related ideas like African ways of knowing have received a great amount of attention. The claim is that indigenous knowledge, African ways of knowing, etc. have been rejected, ignored, undervalued, or colonised ${ }^{1}$ - that is, exploited for Western (or Northern) ends and purposes. Second, the notions of diverse epistemologies and epistemological diversity have had both broad and deep coverage, especially in terms of the training, the socialisation into research, received by postgraduate, notably doctoral students in African universities. There is some ambiguity here, in that "epistemological diversity" has been employed, variously, to refer to beliefs and belief systems; methodological diversity, or diversity in research method(ologie)s; diversity of research questions; diversity of researchers and their cultures; and varieties of theoretical knowledge, and knowledge perspectives.

What is arguably characteristic of African conceptions of knowledge is a strong relational element that is also found in African ontology and ethics. Coming to know is understood as a process of persons developing insights about one another and with all that exists. This indicates not only an intimate relationship between knower and known, between what it is to know and what it is to be known but in effect also a communalist understanding of knowledge: I know because we know. Or, a knower is a knower because of other knowers.

(C) KONINKLIJKE BRILL NV, LEIDEN, 2021 | DOI: 10.1163/9789004442108_004 
This understanding of knowledge relations and knowledge communities then serves to validate indigenous insights and multitudinous ways of knowing, alternative conceptions of knowledge and epistemological diversity. At the heart of most if not all epistemological debates regarding African higher education is a reclamation project that is significantly concerned with decolonisation and Africanisation.

Notwithstanding the political and ethical tenability and legitimacy of this project, my concerns have been (and continue to be) the following: that indigenous knowledge discourses have tended towards an implicit or explicit endorsement of relativism (both about knowledge and about truth; see also Broadbent, 2017) and/or validation of all kinds of superstition (Horsthemke, 2004a, 2004b, 2014), and that preoccupation with diverse epistemologies or epistemological diversity has tended towards a misuse of "epistemology" and "epistemological" (Horsthemke, 2017). In the present chapter, I focus on recent publications on these topics. Among these contributions are some of the chapters commissioned for Gloria Emeagwali and Edward Shizha's coedited anthology, African Indigenous Knowledge and the Sciences: Journeys into the Past and Present (2016), as well as for a two-part anthology co-edited by Michael Cross and Amasa Ndofirepi (2017), Knowledge and Change in African Universities.

Indigenous Knowledge, African Ways of Knowing, and Higher Education

Postcolonial higher education on the African continent has been characterised, amongst many other concerns, by the imperatives of transformation and decolonisation. The entirely understandable and plausible concern has been with the initiation of a set of fundamental changes in higher education that would reflect Africa's transition from downtrodden, omni-oppressed and exploited victims of colonialism and slavery to full-fledged membership and partnership in the global community. The changes envisaged for higher education include mentioning just a few major criteria and challenges, demographic changes (composition of the student, teacher and administrative body profiles of universities and other institutions of higher learning); changes in the syllabus, the content of what is taught, guided by an imperative of relevance, of social and cultural (including linguistic) appropriateness; changes in the curriculum, how teaching and learning, on the whole, are organised, including the language of instruction (see Brock-Utne, 2017; Ramoupi \& Ntongwe, 2017); as well as changes in the criteria of what counts as excellence in research, 
acceptable throughput rates, and the like. A significant component of the decolonisation and, in effect, the Africanisation of higher education has to do with knowledge, the retrieval, reclamation and recognition of indigenous, subaltern and diverse knowledge (systems) and epistemologies. ${ }^{2}$

The debate about indigenous knowledge, which arguably became a serious academic topic some 30-40 years ago, continues unabated. Perhaps the term "debate" is not altogether correct. While there have been some critical voices (see, for example, Horsthemke passim; Metz, 2017, pp. 28-30), a brief review of recent publications indicates that the references to "indigenous knowledge," "African ways of knowing," etc. still proceed largely without the requisite philosophical reflection and epistemological analysis. It is to these publications that I now turn.

The chapters collected in Emeagwali and Shizha's co-edited anthology, African indigenous knowledge and the Sciences: Journeys into the past and present (2016), focus on Africa's contribution to science - technology, physics, astronomy, medicine, metallurgy, architecture, as well as musicology - and explicit or implicitly call for the inclusion of indigenous or African science and technology in academic syllabi and curricula. Cross and Nofirepi's Knowledge and change in African universities (2017) is an anthology expressly concerned with the transformation of Africa's higher education landscape and contains several chapters that emphasise the decolonising, transformational function of indigenous, African knowledge (systems). Other recent, related contributions include Njabulo Bruce Khumalo and Charity Baloyi (2017), Hassan Kaya and Yonah Seleti (2013), and Kaya's (2013, 2014) respective emphasis on African indigenous knowledge, and Moyra Keane and Constance Khupe (2016, 2017), Lesley Le Grange (2016), and Savo Heleta's (2016) respective essays on decolonisation and higher education.

As I indicated above, the purpose behind appeals to indigenous knowledge, advocacy of African ways of knowing, Africanisation of knowledge, etc. is largely uncontroversial: it involves "re-appropriation of the production and dissemination of knowledge in universities in Africa" (Ramoupi \& Ntongwe, 2017, p. 197), retrieval, reclamation, a quest for recognition, relevance (see Kaya \& Seleti, 2013; Nodirepi \& Cross, 2017a, p. 9, 2017b, p. 52) and appropriateness, following centuries of especially brutal subjugation, oppression and exploitation of Africans. Of course, the quest for relevance and appropriateness of syllabus and curriculum content ought not to be interpreted too narrowly. There may still be great value in teaching and learning about "dead white males," just as a curriculum devoted entirely to, say, social media, hip-hop, R'n'B and brand shopping may prove uneducative, even if this is what is relevant, insofar as this is what young people gravitate towards anyway, i.e. independently 
of institutional prompting. However, the emphasis on indigenous languages, both as the medium of instruction and the object of analysis, on social and cultural history, the acquisition of traditional skills, etc. may indeed prove to be enriching all educational contexts on the continent. This, however, takes us to the deeper issues.

The real problem resides with the understanding and concept of knowledge that is at work here. Advocates of indigenous knowledge and African ways of knowing to devote a considerable amount of energy, time and space to explain their understanding of "indigenous" and "African" - but generally appear to assume that the concept of knowledge requires no further elaboration. ${ }^{3}$ Only Ndofirepi and Cross (2017a, p. 2) have bothered to provide an analysis - which, however, I regret having to say, is not altogether accurate. They distinguish between three ways of knowledge or knowing, "knowing that (knowledge by acquaintance) ... knowledge of what ... permitting the knower access to definitions, meanings, and special characteristics of some content ... [and] knowledge of how (know-how), [which] refers to having the practical and theoretical instruments that are necessary to perform a particular activity with a certain level of skill." The authors err in equating knowing that with knowledge by acquaintance, and again in suggesting that knowledge-what is a distinct form of knowledge. Questions and issues of knowledge-what are reducible to questions and issues of knowledge-that: if I know what a particular word means, then I know what it means $x$. Knowing-that is also referred to as theoretical, factual or propositional knowledge. The object of my knowledge, in other words, has propositional content. It is distinct not only from knowing-how, which is indeed practical or skill-type knowledge, but also from knowledge as an acquaintance, or familiarity: i.e. knowledge of person, places, etc. ${ }^{4}$ Occasionally, the different ways of knowing may overlap. Thus, language skills may be characterised both in terms of practical knowledge and acquaintance: if I know (i.e. if I am acquainted or familiar with) a particular language, then this implies that I can speak and/or read it. Similarly, if I know how to bake bread, then I know that I require certain ingredients and utensils and that I am familiar with certain facts about the dough, baking temperature and duration, etc. Ndofirepi and Cross also fail to list, let alone analyse, the components or conditions of knowledge-that, which are belief, (adequate) justification, and truth. ${ }^{5}$ In other words, if I know that $x$, then I believe that $x$; I have adequate justification for believing that $x$; and $x$ is true. The authors are right, of course, in saying that the three-fold understanding of knowledge is "at the heart of any real discourse on the nature and role of universities" (pp. 2-3). Unfortunately, this sound piece of advice is not commonly heeded by advocates of indigenous knowledge and African ways of knowing. ${ }^{6}$ 
In applying this understanding to the ideas in question, we would now ask, "Could there be African indigenous acquaintance or familiarity type knowledge? practical knowledge or skills? theoretical, factual or propositional knowledge?" It might be instructive to examine, in this regard, the "long-standing traditions and practices" Kaya (2013, p. 136) associates with the concept of African Indigenous Knowledge Systems (AIKS): "the skills, innovations, wisdom, teachings, experiences, beliefs, language and insights of the people, produced, and accumulated over years and applied to maintain or improve their livelihood." He adds, "Some forms of AIKs such as experiences, wisdom, beliefs, etc. are expressed through stories, legends, proverbs, folklore, rituals, songs, etc." (see also Kaya \& Seleti, 2014, pp. 33, 35; Kaya, 2014, p. 91). African indigenous knowledge in the acquaintance or familiarity sense can plausibly be taken to cover "stories, legends, proverbs, folklore, rituals, songs, etc.," as well as familiarity with local languages. Language skills and other skills and practices can be classed with African indigenous knowledge-how or practical knowledge. It makes excellent sense, for example, to speak of the skills of the San, or the practical knowledge of the Dogon. The real problem arises with beliefs, teachings, experiences, wisdom, and innovations. Both beliefs and teachings could be false, or untrue, and/or insufficiently justified (and, either way, beliefs make up only part of knowledge) - and could therefore not be considered knowledge in the propositional sense, i.e. knowledge-that. Insofar as experiences constitute "justification," they constitute only one component (albeit a significant one) of propositional knowledge. Besides, what about wisdom and innovations? Innovations are the results of applying knowledge, so do not qualify as knowledge per se. Wisdom is a much more slippery concept. New age normative advice and aphorisms are often passed for "wisdom" while remaining in essence either platitudes or unprovable, or both. In cases where wisdom can be said to constitute knowledge-that, the question then is, in what way it could be considered "African" or "indigenous." This, then, points to a central problem: if something qualifies as knowledge-that, then how could it possibly still be referred to as "African" or "indigenous"? There could be, and are, African or indigenous beliefs (beliefs in ancestor agency, beliefs about the hierarchy of beings, or beliefs about the origin of the earth and the stars, etc.). Even if it were admitted that there could be something like African or indigenous justification (constituted by, say, the testimony of elders; or evidence available only to the initiated), this would not suffice for calling it knowledge. Truth is arguably the key component here. If something is false, or untrue, then it will not qualify as knowledge. To consider truth as necessarily perspectival, personal, or relative to society or culture, to think that there could be African indigenous truth or truths, that truth can be (and indeed needs to be) "decolonised" 
(Suárez-Krabbe, 2017, p. 62), is to open the floodgates to substantial problems. If truth is in the eye of the societally or culturally located beholder, we could not speak about the "transatlantic slave trade," "coloniality" (ibid.), or about the under-funding of African universities ${ }^{7}$, in transculturally-compelling terms. If nothing else (but of course there are substantial logical problems), this diminishes the value and impact of any verdict. The deep logical problem can be illustrated regarding Sarah Chiumbu's observation, "We have to recognise that there is no single epistemic tradition from which to arrive truth or universality" (2017, p. 3; emphasis added). What is the status of this view? From which particular "epistemic tradition" does it obtain its validity? Why, then, should "we" who come from a different epistemic tradition "have to recognise" or accept this? Is it perhaps true? Does it hold universally? And if this does indeed exemplify a universal truth and, as such, is compelling beyond particular "epistemic traditions," then why should there not be other binding universal truths?

Referring to participative "indigenous, African research methodology," Khupe and Keane (2017) assert,

Standard notions of validity are thrown into question. 'Truths' are defined not only as factual truths and representational truths but also as healing truths. ... For the research process to be truly participative, respectful challenge needs to be directed across the whole research community's input and assumptions. Such robust engagement guards against romanticising IK systems helps to acknowledge changing contexts and allows for multiple truths. (p. 34)

It is difficult to make sense of this understanding of truth, i.e. as necessarily constituted by "multiple truths." Can a "healing truth" that is not also factual even have the status of "truth"? I suspect that what the authors are referring to in all these cases is not "truths" but, rather, "beliefs."

I do not want to believe or be able to say things that are then passed-off as "my truth," or that are considered to be "true for me," or "true for or within my society or culture." If I say something that I consider to be true, that I believe sincerely and intensely, but that contravenes basic common sense and reason or that involves certain blind spots or blank spots on my part, this should be pointed out to me, criticised and rejected based on available evidence, and of norms and rules of argumentation that apply to all language users, all those participating in relevant discursive exchanges. Epistemic justice demands nothing less than this. (On the same basis, I want to be able to engage critically with what is believed or stated within and also outside of my society or culture, and not to have to accept it merely because of majoritarian consensus, 
nor for spurious reasons of "political correctness.") When I abandon or change my beliefs, as a result of such criticism or rejection, this arguably constitutes a qualitative change, indeed progress - just like the transition from a geocentric to a heliocentric worldview constitutes progress, something a consistent and rigorous relativism would reject, at least implicitly. What I (have come to) know is different from superstition, bias, and prejudice. My knowledge may have a particular historical and geographical source, a particular origin both in time and in space, but once I know something, once it qualifies as "knowledge," it is no longer "local," or "aboriginal," or "indigenous" - it is, purely and simply, knowledge.

When Sipho Seepe (2017, pp. 134, 135) refers to "the symbiotic relationship between knowledge and power" and to the contextual nature of knowledge production and "the contours in which it is produced," he does not establish what makes something "knowledge." Nor does Michael Kariwo (2017, p. 63; see also pp. 64, 65), despite acknowledging that "what remains problematic and contested is the definition of knowledge itself." According to Kariwo, "one way of defining knowledge is by examining the "performativity" of knowledge that is its instrumental capacity to address everyday problems" (p. 66). This instrumental capacity might be one of the incidental characteristics of both propositional and practical knowledge. However, it does not constitute a defining criterion. Even if Kariwo is correct, as for the sake of argument one might assume he is, in asserting that "knowledge production ... is intricately connected with power and politics" (p. 67; emphasis added), this does not mean that knowledge cannot be conceived of independently of "power and politics." It is not knowledge per se that "derives a great deal of its legitimation from the decisions of the state" (Seepe, 2017, p. 135) but, rather, knowledge claims. It is only the latter (not knowledge as such) that can be considered exemplary of cultural dominance or power, hegemonic or counter-hegemonic, invasive or non-invasive, invalid or valid, illegitimate or legitimate.

When Kariwo (2017, p. 76) contends, on the subject of "colonial knowledge" and "Western scientific knowledge," that the "science curricula adopted by many African countries are transplants which were not suitable for African indigenous nations because ... they [were] irrelevant in terms of addressing critical issues such as poverty," one wonders whether the function of a science curriculum is to address socio-political problems like poverty. Lesley Le Grange and Glen Aikenhead's concern (2017, p. 32) "has been (and is) with critiquing the dominance of Eurocentric sciences, arguing that its dominance is not because of its purported superior rationality, but because of European imperialism and colonialism - that its hegemony, as well as its appearance of universal truth and rationality, are primarily the outcome of military, economic and 
political power of European cultures." But can one actually speak of "Eurocentric sciences"? Like Seepe and Kariwo, the authors appear to be committing a category mistake, by conflating issues in epistemology and issues in social justice.

"African indigenous knowledge fulfills the expectations about science," according to Shizha and Emeagwali (2016, p. x). As an example, they draw attention to ancient Egyptians' "mastery of medicine [that] is celebrated in a variety of scrolls" (Emeagwali \& Shizha, 2016, p. 4). They mention

careful discussions of injuries to the top of the head; injuries to the face; injuries to the jaw, neck, thorax, spine and arm; the names of human body parts and anatomy; neurological symptoms; the earliest known description of the brain; the first description of the meninges and brain pulsations; and a clear familiarity with the nervous system, blood circulation and the cardiovascular system. But even so, Egyptian medicine was holistic and reflected a preoccupation with the supernatural, the divine and ancestral forces, in a manner that is quite familiar to scholars of [AIKS]. Invocations and prayers accompanied medication and were believed to be vital and indispensable for the medication to work effectively .... (p. 5)

This passage is illuminating for several reasons. On the one hand, it refers to what generally seems to count as "expectations of science," i.e. scientific evidence, observation, documentation and description, and precise labelling. (Then what makes it "African indigenous" knowledge? Is it only the fact, if it is a fact that it originated in the northern part of the African continent?) On the other hand, the reference to "supernatural, the divine and ancestral forces," "invocations and prayers," etc. indicates a substantial problem, namely that in indigenous knowledge discourses it is difficult, if not impossible, to distinguish between science and superstition. A second problem is manifest in the following extracts:

Each society has its own way of categorizing and labelling types of knowledge. ... Different cultures have different ways of experiencing social reality and, hence, different ways of categorising knowledge ... This is influenced by their worldview and belief systems as well as perceptions about the natural environment, including the socio-economic and ecological context of their livelihoods .... (pp. 6, 7)

Almost all knowledge has cultural relevance and must be examined for its particular focus without universalising it in the manner that western scientific thought and methodologies seek to do. ... Indigenous African 
science is unique to each African society, although there may be commonalities within these bodies of knowledge. We should acknowledge that even in African societies themselves, there are different forms of scientific knowledge since each society may have its own way of viewing social reality and its own way of interacting with the natural world. (pp. 8, 9)

Does this mean that all societies' and cultures' ways of categorising and labelling types of knowledge, experiences and perceptions, worldviews and belief systems are equally valid? Is there no yardstick for claiming that a particular perception might be mistaken, for criticising and rejecting a particular worldview? (Think of geocentric, flat-earth and/or creationist worldviews in this regard.) It would seem that defenders of AIKs are committed to a throughgoing cultural and epistemological relativism. Finally, if "western science" has misrecognised or failed to recognise the creativity and insights of other societies and cultures and has perpetuated "misconceptions about the African indigenous knowledge" (p. 6), then similar misconceptions are at work within indigenous knowledge advocacy: "While science, from a western, theoretical and methodological perspective, is judged from a positivist approach, indigenous science is defined from its holistic and utility perspective" (p. 7) and "is primarily concerned with the utility, accessibility and practicability of knowledge" (p. 9). This characterisation of "western science" is little more than an outdated caricature that also fails to acknowledge sincere and reputable endeavours towards holism and practical usefulness within mainstream academic contexts.

\section{3}

\section{Epistemology and Diversity}

Given the understanding of knowledge as relational and as communal, and given the sheer diversity of relations and communities, it should come as no surprise that the idea of epistemological diversity has special resonance on the African continent. This appears to tally with the consideration that one of the most important things that faculties of research universities can do is to prepare students for epistemological diversity. The idea is that educational researchers, in particular, need to be socialised into understanding and engaging with one another, both within and across research communities. Thus, to prevent a recurring pattern of epistemological single-mindedness, researchers would need to engage with diverse epistemological perspectives to the extent that members of different research practices can understand one another, 
despite or perhaps through their differences. For reasons of conceptual clarity, however, one ought to distinguish between two different conceptions of epistemological diversity at work here, between diversity across communities, cultures, ethnicities, etc. on the one hand, and different normative theories of knowledge on the other (epistemological foundationalism: e.g. naturalism, empiricism, positivism, and rationalism; and antifoundationalism, e.g. pragmatism, interpretivism, epistemological standpoint theory, etc.). In what follows, my focus will be on the former, i.e. on community-, culture-, and ethnicity-based "epistemologies." This is the conception that underlies reference to African and Afrocentric epistemologies, "indigenous African women's epistemologies," "Afrocentric feminist epistemology," and the like (see Horsthemke, 2017 , pp. 107, 115), usually defined in opposition to "Western" or "Northern epistemologies" (Le Grange, 2016, p. 9; Brock-Utne, 2017, p. 175; Ramoupi \& Ntongwe, 2017, p. 196). Thus, for Le Grange (2016, p. 10), one possibility of decolonising the university curriculum is "for students to learn together about the origin of human beings, and the epistemologies that emerged from the Cradle of Humankind that Nabudere (2011, p. 159) refers to as Afrikology." As Neo Lekgotlalaga Ramoupi and Roland Ndille Ntongwe (2017, p. 212) put it, "Only when these epistemologies are Africa inspired and generated can we talk of the African university"? ${ }^{8}$ Felix Maringe (2017, pp. 3, 5) posits that "the new African university" requires not only incorporation and development of "indigenous knowledge systems and methodologies as authentic, priority knowledge generation systems" but also the development of "local" and "different critical epistemologies." Cross-and Ndofirepi (2017, pp. 89, 86) refers to "emancipatory epistemologies" and to the "centrality of alternative epistemologies in reasserting the transformative potential of knowledge."

What, then, is "epistemological diversity"? The phrase is often used to refer to (1) different beliefs and belief systems, (2) methodological diversity, i.e. diverse methods of inquiry and research methodologies, (3) diversity of research foci, and/or (4) diversity of researchers and their cultures. In all these cases, the diversity in question is fairly uncontroversial. Beliefs and belief systems vary, as do research methodologies, methods of inquiry, ${ }^{9}$ and research foci. There is also great diversity among researchers and their social and cultural backgrounds. But none of these examples reflect the common philosophical understanding of epistemology (see Siegel, 2012, pp. 66-74). When philosophers refer to epistemology, they are usually concerned neither with describing a system or stock of beliefs nor with how beliefs are acquired. They characteristically refer to epistemology as a normative field of inquiry, i.e. what ought and ought not to be called knowledge. In other words, "knowledge" is not ambiguous between various concepts of knowledge. What constitutes knowledge does 
not fluctuate with differences in people's reasoning abilities or with what their constructs are. This view, it should be noted, is compatible with the insight that people are not all on the same footing as far as cognitive resources, skills and opportunities are concerned. This insight permits us to talk of different levels of knowledge, without implying relativism. Philosophers are also concerned with epistemology as a normative theory of knowledge, a particular set of ideas about knowledge and inquiry. As I indicated earlier, the philosophical tradition comprises different epistemologies. For example, a foundationalist and non-foundationalist epistemologies coexist, because philosophers still disagree about them, even though they agree that only one position (e.g. rationalism, empiricism, or pragmatism) can be correct (see Levisohn \& Phillips, 2012, pp. 44-55). If "epistemological diversity," however, is employed to refer to (5) different epistemologies and epistemological perspectives that (as their defenders contend) are all equally respectable and valid, serious problems arise.

In the accounts of community-, culture-, ethnicity- and gender-based epistemologies cited earlier, the central issue remains unexplored, namely what makes something an epistemology. Is the term "epistemology" perhaps being misused in postmodern and postcolonial thought and literature? Epistemology is a complex field that has evolved over a lengthy period, and there is a persistent concern that the basic questions and topics in epistemology are being sidelined, if not ignored altogether. Some pertinent philosophical questions are: What exactly do postmodernist and postcolonialist claims about epistemological diversity mean? Do these diverse ways of grounding knowledge withstand thorough, critical scrutiny? How are they connected with traditional epistemological distinctions, e.g. between knowledge and belief, between normative and descriptive inquiry, and with essential epistemological components like warrant, justification and truth?

The traditional meaning of epistemology is theory of knowledge, i.e. "logic of knowledge" (episteme - knowledge; logos - word). Since Plato and Aristotle, there has been general agreement among epistemologists about a fundamental distinction between knowledge and belief/opinion (Horsthemke, 2017, p. 110). It should be noted that in Yoruba, too, pertinent distinctions are made. Gbàgbó (belief) may become mò (knowledge). Gbàgbó that is not open to verification and must, therefore, be evaluated based on justification alone (àlàyé, papò, etc.) cannot, in the absence of óótó (truth), be considered mò (see Hallen \& Sodipo, 1997, p. 81). Do indigenous African women have a theory of knowledge? It seems exceedingly unlikely that they do. They have knowledge in the acquaintance, practical and propositional senses, but hardly an epistemology in the philosophically relevant sense that sets them apart as indigenous African women. In maintaining this, of course, I might now be accused of Western 
or Eurocentric arrogance, and of epistemic violence (see Heleta, 2016), in the sense of deliberate, principled non-recognition, if not discursive infliction of harm on subjects.

"Western Arrogance," "Eurocentrism," “White Doubts" and Fears, and "Epistemic Violence": The Responses

The charge of epistemic violence is certainly serious - if and when it is applicable. I take it, following Heleta (2016, p. 2), to be directed against Eurocentrism and the continued "reinforcement of white and Western dominance and privilege," stereotyping, "prejudices and patronising views about Africa and its people."

Is the "perception of African indigenous knowledge as mere repetition of practices without any theory to explain them" an example of "Eurocentric prejudices" (Kaya \& Seleti, 2013, p. 33), of "Western cultural and intellectual arrogance" (p. 31), of a failure to understand the "holistic nature [of] AIKs" (Kaya, 2013, p. 138) and "African traditional education which does separate theory from practice, especially its community-based nature" (Kaya \& Seleti, 2013, p. 36)? The charge of "Eurocentric" or "Western arrogance" is often legitimate, especially when it proceeds without any theory or conceptual framework of its own. I do not think, however, that my critique can be dismissed in this fashion. It constitutes a challenge to defenders of AIKS to engage with my analysis of knowledge and with my concerns and to furnish a relevant and plausible understanding of knowledge and epistemology. Nor do I think that a simple reference to the separation of theory and practice will do.

Dismas Masolo (2014, pp. 202-208) takes issue with my scepticism about indigenous knowledge (Horsthemke, 2014), which I expressed during a colloquium on his book, Self and community in a changing world, held at the University of Johannesburg, South Africa, in March 2012. Among other things, his contentions are the following:

- that I appear "unduly to think that knowledge is only about empirical claims. The world of humans is made of far more than a preoccupation with just empirical claims about "the world," or only with the truth value of such claims. Objects may be the same to a group of people who populate a particular region, but it does not follow that everyone in that region thinks only of the same atomic facts out of such objects even if it would make sense to them when made. Horsthemke's argument rests implausibly on a reductionist definition of "experience" as pure somatic movements of nerves, muscles, lenses, and so on. In other words, the meaning of "experiencing objects" would have to be restricted to what occurs when we encounter one 
in empirical senses alone; but is it? ... The idea of indigenous knowledge is far broader than how people express concerns or make claims about empirical reality. It is also about people's creative transformation of the physical world around them in response to their needs, and it is also about how people design norms of conduct to regulate their relations as well as access to and distribution of resources" (pp. 203-205);

- "that the term "indigenous" is not a synonym for "non-Western" or "nonmodern," although it was given these connotations in colonial language and literature. Its variant, "native," is equally common. ... On the other hand, assuming that it is indeed a form of indigenous knowledge, then what would exempt the definition of knowledge as "justified true belief" from being an example of indigenous Western knowledge?” (pp. 207, 208).

Two quick responses will have to suffice. First, although I consider empirical claims to be of fundamental significance in knowledge, I do not think I have ever advocated any kind of exclusive, reductionist account of the experience. I do think, for reasons I cannot go into here, that it makes excellent sense to speak of moral knowledge (even of moral truth and facts). Nor do I deny the cognitive force of feelings and emotions. Second, the definition of knowledge as "justified true belief" resonates with distinctions made in Yoruba and in ancient Egypt (which may well have had a profound influence on Greek and generally occidental beliefs and values). Even if it is accepted, purely for argument's sake, that this definition is an example of "Western knowledge," in the sense that it originated in the "West," it has the immense virtue of being internally consistent and logically coherent. It is, in fact, universally (or at least translocally) applicable.

Against what Khupe and Keane (2017, p. 27) have referred to as my "universalist ... way of understanding knowledge," they propose a "pluralist" view of "knowledge as a socio-cultural and historical construction": "From a pluralist perspective, what qualifies as knowledge depends on how particular societies categorise, code, process, and assign meaning to their experiences." This way of understanding knowledge also has normative implications for research: "research among African people must be characterised by flexibility, participation, and negotiated purposes ..., and should seek to interrupt colonising forms of research by focusing on African thought and experience" (emphasis added). It is not at all clear how Khupe and Keane's favoured view of knowledge and research can avoid the dual threat of relativism and parochialism - with all the attendant problems.

In Maringe's account of the transformation of knowledge production systems in "the new African university" (2017, p. 15), he refers to my argument (Horsthemke, 2004a) "that IKs involves at best an incomplete, partial, or at 
worst, a questionable understanding or conceptualisation of knowledge and ... that as a concept, it has questionable relevance to the debates around real issues of transformation." He then declares that he disagrees "completely with these sentiments, as, in [Maringe's] view, they represent overtures by "white doubters" - those who are scared of ceding control of the academy and seek to cement the hegemony of the west as the only legitimate players in shaping transformational discourses in the African university." Maringe's characterisation of my ("white") doubts is correct. I am indeed sceptical about the idea of indigenous knowledge, for reasons given earlier in this chapter. However, these are not "sentiments," as Maringe suggests, but the results of careful reasoning and circumspect argumentation, guided entirely by both philosophical scrutiny and examination of the available evidence - and not by any fear of ceding control or any hegemonic impulses. I am not opposed to transformation, and I have nothing to gain from any such opposition - but I am opposed to irrational beliefs, weak justification, dodgy reasoning, and fashionable assertions that parade as liberatory and transformative discourse. To rise above plain namecalling, Maringe would have done well to engage with my philosophical, epistemological analysis and not merely dwell on a set of pat assumptions about critics' and sceptics' motivation.

Concluding Thoughts: Epistemological Dimensions of African Higher Education in the 21st Century

Emily Robertson (2013, p. 300) argues that diversity is both an epistemic and a moral virtue, but that this argument "does not support alternative epistemologies, cognitive relativism, or the replacement of truth as an epistemic goal by, for example, beliefs that have progressive consequences." The value of diversity for knowledge resides in the possibility of different groups having "different experiences that lead them to know or believe things that escape others' attention": reports of their experiences may function as data that allows researchers to examine the social system or structure from their social location (p. 304).

While postcolonial theory arguably errs in postulating the existence of diverse knowledges and truths, the diversity in question is conceivably generated by (characteristically) practical epistemic priorities - priorities that emanate from different lived experiences, individual as well as social and cultural. A plausible view appears to be that knowledge and truth do not fluctuate, that they remain invariant across individuals, societies and cultures, but that there may well be distinctive sets of epistemic concerns that arise from particular personal, historical and socio-political circumstances. If it is correct to assume 
that practical epistemic and educational priorities will emerge from life experiences and from the ways these are socially articulated, then one might assume that, given the different life experiences of people across the globe, the practical epistemic and educational priorities will also differ.

Given the experience of "indigenous" Africans of wide-ranging cognitive injustice, it stands to reason that they would have as priorities matters of epistemic transformation and redress. If epistemic and educational concerns and priorities arise from different forms of social life, then those that have emerged from a social system in which a particular race or group has been subordinate to another deserve special scrutiny. Given the (especially vicious) history of physical and psychological colonisation, it is plausible that one of the epistemic and educational priorities will be to educate against the development of a subordinate or inferior mindset, as well as against a victim and beggar mentality, despite the continuing economic crisis and low level of economic growth. An additional priority arises with Africa's low literacy quotients. In many countries, the language of conceptualisation and education is the official language of administration: English, French or Portuguese, in which the majority of children and learners are not primarily competent. Consequently, there exist few successes in learning; quality and efficiency suffer, and high repeat and dropout rates mean a squandering of available resources. While it does not follow that particular historical and socio-economic circumstances yield or bestow automatic validation or justification of (the content and objectives of) an "African epistemology," an idea like "decolonisation of African minds" has a particular resonance here. Rather than implying a "post-truth" epistemology, it involves "going back to one's language" in "thinking about thinking," critically examining one's "own ways of conceptualisation" as well as the ways of conceptualisation prevalent in one's culture - in short, it involves "philosophising."

If what has been established above is cogent, it follows that so-called "epistemological diversity" refers neither to a multitude of truths nor to an "anything goes" conception of justification, but rather to different experiences connected to particular social locations, or - as Robertson puts it - to different social pathways to knowledge (note the singular!). In this sense, the reference to "epistemologies" - like the reference to "plural systems of knowledges" or to indigenous, local or subaltern ways of knowing - is not only unhelpful but also misleading.

The promise of a social epistemology for the real world, then, has in part to do with context and locality - but not in terms of any exclusionist, "hands-off" approach. Rather, it appears to be plausible that the particular historical, geographic and socio-cultural experiences of people give rise to particular priorities that shape their epistemic theory and practice - and also yield conceptual tools that are likely to enrich epistemology as a whole. 


\section{Notes}

1 Thus, "the works of Le Grange and Aikenhead have been essentially concerned with critiquing the marginalisation, denigration and decimation of indigenous knowledges" (Le Grange \& Aikenhead, 2017, p. 32). The authors assume, without providing any argument, that the notion of "indigenous knowledges" is a meaningful one.

2 On the first three kinds of change or transformation see Garuba (2015), who contends that a transformed, "African curriculum" involves a "pedagogy that brings the knowledge of the marginalised to bear on our teaching."

3 For the provision of examples see the literature review in Khumalo and Baloyi (2017, p. 2); see also Lanzano (2013, pp. 4, 5). Despite its promising title, What kind of knowledge is indigenous knowledge'?, the latter article does not provide an analysis of the concept of knowledge, and only contains isolated mention of "beliefs ... interpreted as 'customary' or 'traditional' apparatuses" and "local practices" (p. 9), but without explicitly relating these to an understanding of knowledge. The examples Lanzano furnishes (sacred sites, ritual practices, and pertinent rules and prohibitions) could more accurately be viewed as superstitions and fairly arbitrary directives rather than knowledge.

4 Kariwo (2017, p. 66) suggests,

From a Western perspective knowledge is factual, theoretical and technical ... There is also a distinction between codified knowledge and tacit knowledge.

This analysis is misleading, since factual and theoretical knowledge are identical. Technical knowledge may be theoretical (factual), but it may also be practical - as may so-called "tacit knowledge." So-called "codified knowledge" is necessarily theoretical.

5 A additional problem is contained in the authors' reference to "truthful knowledge" (Cross \& Ndofirepi, 2017, pp. 84, 85). Knowledge in the propositional sense cannot be anything but truthful: if it is not truthful it is not knowledge. For similar reasons, given the necessity of the justification condition for knowledge-that, any reference to 'legitimate knowledge' involves a tautology. In this sense, Keane, Khupe and Muza's reference to "the validation of local knowledge" (2016, p. 177; see also Keane, Khupe, \& Seehawer, 2017, p. 15; Khupe \& Keane, 2017, p. 26) is misleading, not only because of the qualifying adjective but also because of the implication that knowledge could be invalid. Their point is more convincingly made by replacing 'validation' with 'recognition'

6 Kaya (2013, p. 150; see also pp. 135, 136) claims to conduct a "critical analysis of the challenges and prospects of integrating AIKS into higher education in South Africa and Africa at large," challenges that "lack of a conceptual framework to provide a clear African indigenous perspective and definition of the concept 'knowledge." Regrettably, he provides neither a critical analysis nor requisite definition (see also Kaya \& Seleti, 2013, pp. 30, 31).

7 According to Maringe (2017, p. 14), "The truth is that ... many universities in Africa are poorly funded."

8 It is worth noting here what might be called the fallacy of the collective singular, the implication that there is a single, homogeneous institution and system of higher education on the African continent. See also Nofirepi and Cross (2017b) and Maringe (2017), who commit the same error. I use this phrase to refer to an unwarranted generalisation that fails to do justice to the richness and multitude of, for example, African tertiary institutional perspectives, traditions and identities, and curricular practices and innovations (see also Horsthemke, 2017, pp. 104, $117 \mathrm{fn} .4$ ). A similar objection might be made with regard to references to "the African child" (Maringe, 2017, p. 4). 
9 This should not be taken to imply some kind of methodological relativism (Siegel, 2012, p. 69). There are legitimate and illegitimate ways of conducting research, just as there are good or bad, incorrect or incorrect research methods, better or worse ways of proceeding.

\section{References}

Broadbent, A. (2017, June 1). It will take critical, thorough scrutiny to truly decolonise knowledge. The Conversation.

Brock-Utne, B. (2017). Decolonisation of knowledge in the African university. In M. Cross \& A. Ndofirepi (Eds.), Knowledge and change in African universities: Volume 1-Current debates (pp. 161-181). Sense Publishers.

Chiumbu, S. (2017, May 2). Why decolonise research methods? Some initial thoughts. HSRC Seminar, pp. 1-5. Retrieved September 20, 2018, from https://www.hsrc.ac.za/ en/research-outputs/ktreedoc/18320

Cross, M., \& Ndofirepi, A. (2017). Critical scholarship in South Africa: Considerations of epistemology, theory and method. In M. Cross \& A. Ndofirepi (Eds.), Knowledge and change in African universities: Volume 2 - Re-imagining the terrain (pp. 83-100). Sense Publishers.

Cross, M., \& Ndofirepi, A. (Eds.). (2017). Knowledge and change in African universities. Sense Publishers.

Emeagwali, G., \& Shizha, E. (Eds.). (2016). African indigenous knowledge and the Sciences: Journeys into the past and present. Sense Publishers.

Emeagwali, G., \& Shizha, E. (2016). Interconnecting history, African indigenous knowledge systems and science. In G. Emeagwali \& E. Shizha (Eds.), African indigenous knowledge and the Sciences:Journeys into the past and present (pp. 3-11). Sense Publishers.

Garuba, H. (2015, April 17). What is an African curriculum? Mail \& Guardian. Retrieved from https://mg.co.za/article/2015-04-17-what-is-an-african-curriculum/

Hallen, B., \& Sodipo, J. O. (1997). Knowledge, belief, and witchcraft. Analytical experiments in African philosophy (2nd ed.). Stanford University Press.

Heleta, S. (2016). Decolonisation of higher education: Dismantling epistemic violence and Eurocentrism in South Africa. Transformation in Higher Education, 1(1), a9. http://dx. doi.org/10.4102/the.vii1.9

Horsthemke, K. (2004a). 'Indigenous knowledge' - Conceptions and misconceptions. Journal of Education, 32, 31-48.

Horsthemke, K. (2004b). Knowledge, education, and the limits of Africanisation.Journal of Philosophy of Education, $38(4), 571-587$.

Horsthemke, K. (2014). Some doubts about "indigenous knowledge," and the argument from epistemic injustice. In T. Metz (Ed.), Engaging with the philosophy of Dismas A. Masolo. Quest, 25(1-2), 49-76. 
Horsthemke, K. (2017). Africanisation and diverse epistemologies in higher education: Discourses, limitations and possibilities. In M. Cross \& A. Ndofirepi (Eds.), Knowledge and change in African universities: Volume 1 -Current debates (pp. 101-120). Sense Publishers.

Kariwo, M. (2017). Educational policy and the Africanisation of knowledge in the African university. In M. Cross \& A. Ndofirepi (Eds.), Knowledge and change in African universities: Volume 2 - Re-imagining the terrain (pp. 63-82). Sense Publishers.

Kaya, H. O. (2013). Integration of African indigenous knowledge systems into higher education in South Africa: Prospects and challenges. Alternation, 20(1), 135-153.

Kaya, H. O. (2014). Revitalizing African indigenous ways of knowing and knowledge production. In M. Woons (Ed.), Restoring indigenous self-determination: Theoretical and practical approaches (pp. 88-94). E-International Relations.

Kaya, H. O., \& Seleti, Y. N. (2013). African indigenous knowledge systems and the relevance of higher education in South Africa. The International Education Journal: Comparative Perspectives, 12(1), 30-44.

Keane, M., Khupe, C., \& Muza, B. (2016). It matters who you are: Indigenous knowledge research and indigenous knowledge researchers. Education as Change, 20(2), $163-183$.

Keane, M., Khupe, C., \& Seehawer, M. (2017). Decolonising methodology: Who benefits from indigenous knowledge research? Educational Research for Social Change, 6(1), 12-24.

Khumalo, N. B., \& Baloyi, C. (2017). African indigenous knowledge: An underutilised and neglected resource for development. Library Philosophy and Practice (E-Journal), $1-15$.

Khupe, C., \& Keane, M. (2017). Towards an African education research methodology: Decolonising new knowledge. Educational Research for Social Change, 6(1), 25-37.

Lanzano, C. (2013). What kind of knowledge is 'indigenous knowledge'? Critical insights from a case study in Burkina Faso. Transcience, 4(2), 3-18.

Le Grange, L. (2016). Decolonising the university curriculum. South African Journal of Higher Education, $30(2), 1-12$.

Le Grange, L., \& Aikenhead, R. (2017). Rethinking the western tradition: A response to Enslin and Horsthemke. Educational Philosophy and Theory, 49(1), 31-37.

Levisohn, J. A., \& Phillips, D. C. (2012). Charting the reefs: A map of multicultural epistemology. In C. W. Ruitenberg \& D. C. Phillips (Eds.), Education, culture and epistemological diversity: Mapping a contested terrain (pp. 39-63). Springer.

Maringe, F. (2017). Transforming knowledge production systems in the new African university. In M. Cross \& A. Ndofirepi (Eds.), Knowledge and change in African universities: Volume 2 - Re-imagining the terrain (pp.1-18). Sense Publishers.

Masolo, D. (2014). The case for communitarianism: A reply to critics. In T. Metz (Ed.), Engaging with the philosophy of Dismas A. Masolo. Quest, 25(1-2), 185-230. 
Metz, T. (2017). Africanising institutional culture: What is possible and plausible? In M. Cross \& A. Ndofirepi (Eds.), Knowledge and change in African universities: Volume 2 - Re-imagining the terrain (pp. 19-41). Sense Publishers.

Nabudere, D. (2011). Afrikology, philosophy and wholeness: An epistemology. Africa Institute of South Africa.

Ndofirepi, A., \& Cross, M. (2017a). University knowledge for societal change in Africa. In M. Cross \& A. Ndofirepi (Eds.), Knowledge and change in African universities: Volume 1 -Current debates (pp. 1-13). Sense Publishers.

Ndofirepi, A., \& Cross, M. (2017b). Knowledge as a public good: A critical gaze at the African university. In M. Cross \& A. Ndofirepi (Eds.), Knowledge and change in African universities: Volume 1-Current debates (pp. 41-57). Sense Publishers.

Ramoupi, N. L., \& Ntongwe, R. N. (2017). Africanisation of humanities knowledges in the universities in Africa: A critique of the Cameroon and South African experiences. In M. Cross \& A. Ndofirepi (Eds.), Knowledge and change in African universities: Volume 1 - Current debates (pp. 195-214). Sense Publishers.

Robertson, E. (2013). The epistemic value of diversity. Journal of Philosophy of Education, $47(2)$, 299-310.

Seepe, S. (2017). Higher education transformation in South Africa. In M. Cross \& A. Ndofirepi (Eds.), Knowledge and change in African universities: Volume 1-Current debates (pp. 121-143). Sense Publishers.

Shizha, E., \& Emeagwali, G. (2016). Introduction. In G. Emeagwali \& E. Shizha (Eds.), African indigenous knowledge and the sciences: Journeys into the past and present (pp. ix-xi). Sense Publishers.

Siegel, H. (2012). Epistemological diversity and education research: Much ado about nothing much? In C. W. Ruitenberg \& D. C. Phillips (Eds.), Education, culture and epistemological diversity: Mapping a contested terrain (pp. 65-84). Springer.

Suárez-Krabbe, J. (2017). The conditions that make a difference: Decolonial historical realism and the decolonisation of knowledge and education. In M. Cross \& A. Ndofirepi (Eds.), Knowledge and change in African universities: Volume 1-Current debates (pp. 59-8o). Sense Publishers. 